\title{
PEMBERDAYAAN USAHA EKONOMI PRODUKTIF DALAM MENINGKATKAN KESEJAHTERAAN MASYARAKAT PESISIR KELURAHAN KAMPUNG BUGIS, TANJUNGPINANG
}

\section{Empowerment Of Business Productive Economy In Improving Community Welfare Coastal Kelurahan Kampung Bugis, Tanjungpinang}

\author{
Tumpal Manik ${ }^{1 *}$, Hadli Lidya Rikayana ${ }^{1)}$ \\ ${ }^{1}$ Fakultas Ekonomi, Universitas Maritim Raja Ali Haji, Tanjungpinang \\ *Korespondensi : tmanyk@gmail.com dantmanik@umrah.ac.id
}

\begin{abstract}
ABSTRAK
Tujuan penelitian ini adalah untuk mengetahui 1) apakah usaha ekonomi produktif melalui usaha kecil dan menengah maupun kelompok usaha bersama, 2) untuk mengetahui dan menganalsis apakah perberdayaan usaha ekonomi produktif melalui perencanaan, Pelaksanaan, Pengawasan dan Evaluasi dan pengaruhnya terhadap peningkatkan Kesejahteraan dan 3) untuk mengetaui bagaimanakah menumbuhkan semangat berwirausaha dalam Usaha Ekonomi Produktif bagi masyarakat pesisir. Lokasi penelitian dilakukan di Kelurahan kampung Bugis, Tanjungpinang Kepulauan Riau. Data kualitatif yang di kuantifkan sebanyak 55 data yang oleh dengan SPSS V.24 untuk menuji validitas/reabiltas, uji T, Uji F dan uji Determinasi. Hasil penelitian ini membuktikan bahwa usaha ekonomi produktif melalui usaha kecil dan menengah maupun kelompok usaha bersama sudah pernah dilakukan tetapi belum memenuhi tujuan yang akan dicapai. Pemberdayaan usaha ekonomi produktif dalam meningkatkan kesejahteraan masyarakat pesisir berdasarkan pelaksanaan usaha ekonomi produktif berpengaruh signifikan sebesar 36\% terhadap peningkatan kesejahteraan masyarakat pesisir di Kampung Bugis, karena mayarakat dapat melakukan usaha ekonomi rakyat sesuai dengan kemampuan dan keahlian, sehingga mampu menciptakan usaha masyarakat yang bisa diterima lingkungan serta sesuai dengan permintaan kebutuhan masyarakat dan lingkungan saat ini. Sedangkan usaha ekonomi produktif berdasarkan perencanaan, pengawasan dan evaluasi tidak berpengaruh signifikan terhadap peningkatan kesejahteraan masyarakat pesisir di Kampung Bugis, karena kurangnya pembinaan dan pemberdayaan masyarakat untuk pelaksanaan usaha ekonomi produktif. Menumbuhkan semangat usaha ekonomi produktif bagi masyarakat pesisir kelurahan kampung bugis melalui tiga capaian kegiatan antara lain adalah a) Membuat Target Kegiatan, b) Pemberdayaan Masyarakat, c) Pembinaan dan Pengembangan usaha yang kompetitif dan Memperluas akses kepada sumber permodalan khususnya Perbankan dan Lembaga Permodalan Masyarakat lainnya
\end{abstract}

Kata Kunci : Kesejahteraan dan Pemberdayaan Masyarakat, Usaha Ekonomi Produktif, Wirausaha

\begin{abstract}
The purpose of this study was to determine 1) whether productive economic enterprises through small and medium enterprises and joint business groups, 2) to know and analyze whether the empowerment of productive economic enterprises through planning, implementation, supervision and evaluation and its influence on improving Prosperity, and 3) to know how to foster the spirit of entrepreneurship in Productive Economic Enterprises for coastal communities in Kampung Bugis Village. The location of the study was conducted in Kampong Bugis Village, Tanjungpinang Riau
\end{abstract}


Islands. Qualitative data quantified as much as 55 data by SPSS V.24 to test the validity / reliability, T test, $\mathrm{F}$ test and Determination test. The results of this study prove that productive economic enterprises through small and medium enterprises and joint business groups have never been done but have not met the objectives to be achieved. Empowerment of productive economic enterprises in improving the welfare of coastal communities based on the implementation of productive economic enterprises has a significant effect of $36 \%$ on improving the welfare of coastal communities in Bugis Village, because people can do people's economic business in accordance with their abilities and expertise, so as to create a community business that is acceptable to the environment. and in accordance with the demands of the current community and environmental needs. Whereas productive economic enterprises based on planning, supervision and evaluation have no significant effect on improving the welfare of coastal communities in Bugis Village, due to lack of guidance and community empowerment for the implementation of productive economic enterprises. Fostering the spirit of productive economic efforts for coastal communities in the village of Bugis village through three activity achievements, including: a) Creating Activity Targets, b) Community Empowerment, c) Competitive business development and Development and Expanding access to capital sources, especially Banking and other Community Capital Institutions

Keywords: Entrepreneurship, Productive Economic Business, Welfare and Community Empowerment

\section{PENDAHULUAN}

Kelurahan Kampung Bugis, bagian dari Kecamatan Tanjung Pinang Kota di Kota Tanjung Pinang, Provinsi Kepulauan Riau (Kepri) memiliki potensi untuk pengembangan perekonomian masyarakat yang tinggal di daerah pesisir dalam berbagai bidang, baik industri masyarakat kecil-menengah, industri rumah tangga, pengolahan ikan hasil tangkap nelayan, pertanian lahan kering maupun industri pariwisata bahari. Jumlah penduduk 9.086 orang (Kelurahan Kampung Bugis, 2017), atau $10,23 \%$ dari jumlah total penduduk Tanjungpinang, sedangkan jumlah penduduk berdasarkan mata pencaharian 2.816 orang sedangkan sisanya 6.270 (masih sekolah/kuliah dan pengangguran). Masyarakat Kampung Bugis berprofesi yang paling tinggi sebagai buruh harian lepas sebesar $30,50 \%$. Kedua ada adalah sebagai karyawan swasta $46,13 \%$ dan ketiga sebagai nelayan $15,91 \%$.

Tiga sektor unggulan Pembangunan ekonomi Kota Tanjungpinang yaitu perdagangan, industri dan transportasi. Ketiga sektor tersebut diharapkan akan mampu dan dapat merangsang perkembangan serta pertumbuhan sektorsektor usaha ekonomi produktif untuk industri rumah tangga, pengolahan hasil laut dan lading dan kreativitas masyarakat dalam meningkatkan kesjahteraan masyarakat.

Kesulitan meningkatkan kesejahteraan masyaraka yang tinggal didaerah pesisir khususnya para nelayan tradisional karena kurangnya kesempatan untuk mengakses dan menguasai teknologi yang lebih moderen dan tidak dimiliki oleh modal yang cukup adalah faktor-faktor internal yang sering kali menyulitkan usaha-usaha untuk memberdayakan kehidupan masyarakat yang tinggal di daerah pesisir.

Dalam memberdayakan masyarakat yang tinggal didaerah pesisir khususnya Kelurahan Kampung Bugis menjadi lokasi yang strategi untuk meningkatkan kesejahteraan dan perekonomian masyarakat melalui pelaksanaan usaha ekonomi produktif. Perekonomian rakyat yang kuat dan tangguh tergantung dari kemampuan masyarakat untuk mengembangkan sumber daya yang ada dalam lingkungan sekitarnya misalnya dengan meningkatkan kreatifitas industri masyarakat. Perekonomian masyarakat 
yang kuat dengan sendirinya menjadi salah satu penunjang perekonomian daerah dan bahkan perekonomian nasional, maka sudah selayaknya dari kalangan akademisi untuk melakukan kegiatan pengabdian kepada masyarakat untuk memberdayakan masyarakat dalam hal meningkatkan perekonomian masyarakat, khususnya masyarakat yang tinggal di daerah pesisir.

Pengabdian kepada masyarakat ini pada dasarkan untuk meningkatkan kesjahteraan masyarakat yang tidak berdaya menjadi berdaya, mempunyai pengetahuan dan kemampuan dalam memenuhi kebutuhan hidupnya baik yang bersifat fisik, ekonomi, maupun sosial seperti mempunyai kepercayaan diri, mampu menyampaikan aspirasi, mempunyai mata pencaharian, berpartisipasi dalam kegiatan sosial. Berdasarkan uraian diatas, maka penelitian ini melalui kegiatan pengabdian kepada masyarakat tertarik untuk meneliti "Pemberdayaan Usaha Ekonomi Produktif Dalam Meningkatkan Kesejahteraan Masyarakat Persisir Kelurahan Kampung Bugis, Tanjungpinang".

Tujuan penelitian ini adalah, antara lain 1) untuk mengetahui usaha ekonomi produktif melalui usaha kecil dan menengah maupun Kelompok Usaha Bersama pada masyarakat Kelurahan Kampung Bugis, 2) untuk mengetahui dan menganalsis perberdayaan usaha ekonomi produktif melalui perencanaan, Pelaksanaan, Pengawasan dan Evaluasi mampu meningkatkan Kesejahteraan pada masyarakat Kelurahan Kampung Bugis, 3) untuk mengetaui bagaimanakah menumbuhkan semangat berwirausaha dalam Usaha Ekonomi Produktif bagi masyarakat pesisir Kelurahan Kampung Bugis.

\section{METODE}

\section{Waktu dan Tempat}

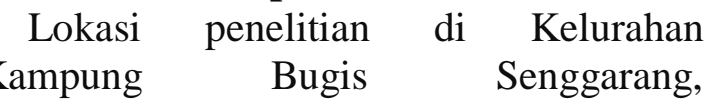

Tanjungpinang Provinsi Kepulauan Riau. Pemilihan lokasi ini karana jumlah total penduduk Tanjungpinang, sedangkan jumlah penduduk berdasarkan mata pencaharian 2.816 orang sedangkan sisanya 6.270 (masih sekolah/kuliah dan pengangguran). Masyarakat Kampung Bugis berprofesi yang paling tinggi sebagai buruh harian lepas sebesar $30,50 \%$. Kedua ada adalah sebagai karyawan swasta $46,13 \%$ dan ketiga sebagai nelayan $15,91 \%$ ingin meneliti lebih lanjut tentang usaha ekonomi produktif

\section{Metode Pelaksanaan dan Analisis Data}

Jenis penelitian ini menggunakan metode kualitatif yang di kuantitatifkan, dengan alat kuesioner diukur atau dihitung secara langsung, yang berupa informasi atau penjelasan yang dinyatakan dalam kuesioner dengan bilangan atau berbentuk angka sesuai dengan tujuan dan varibel penelitian. Dalam alam penelitian ini penulis menggunakan sumber data primer, yaitu data yang langsung dikumpulkan oleh peneliti (petugas survey) dari sumber pertamanya. Adapun yang menjadi sumber data primer dalam penelitian ini adalah Masyarakat yang tinggal di kelurahan kampung Bugis yang terdiri dari nelayan, buruh harian, pkerja kapal dan perikanan, pegawai harian jasa kelautan, Ibu rumah tangga yang memiliki usaha.

\section{Populasi, sampel dan data penelitian}

Polulasi penelitian ini adalah masyarakat yang berhubungan dengan Ekonomi maritim bidang perikanan, pariwisata, perkalapan dan transportasi perhubungan laut. Ekonomi maritim bidang pemberdayaan, pembangunan dan perekonomian masyarakat pesisir, Sehingga populasi menggunakan data jumlah penduduk di Tanjungpinang, Bintan dan Karimun sebanyak 586.596 orang responden $(n=586.596) 2016$ dari data Badan Pusat Statistik Provinsi Kepulauan Riau. 
Sampel penelitian dengan menetapkan responden sebanyak 55 reponden yang disusun secara proporsional dengan jumlah penduduk dan pekerjaan. Jumlah sampel 55 ini menjadi data penelitian yang diproses dan diteliti.

\section{Pelaksanaan kegiatan}

Dalam rangka mencapai tujuan yang tercantum di atas, maka ditempuh langkahlangkah sebagai berikut; 1) Menghubungi Camat Kelurahan Kampung Bugis (pemerintah setempat) untuk mendiskusikan topik yang hendak diabdikan yaitu pemberdayaan usaha ekonomi produktif bagi masyarakat miskin dan mencari data jumlah warga masyarakat yang tergolong miskin sebagai calon peserta pelatihan, 2) Menyelenggarakan pelatihan, dengan materi: Kewirausahaan, Menemukan Peluang Usaha, Manajemen usaha. 3) Peningkatan keterampilan, berupa pelatihan pembuatan produk yang disesuaikan dengan potensi warga masyarakat seperti kuliner, dan kerajinan.

Setelah ditentukan metode pelaksanaan kegiatan diatas, kemudian teknik pelaksanaan kegiatan pengabdian kepada masyarakat ini disesuaikan dengan tahapan kegiatan, yaitu: 1) Observasi (observation) adalah teknik atau pendekatan untuk mendapatkan data primer dengan cara mengamati langsung obyek datanya (Jogianto, 2007), 2) Wawancara (interview) adalah komunikasi dua arah untuk mendapatkan data dari responden (Jogianto, 2007). Dalam kegiatan ini wawancara yang dilakukan bertujuan untuk menghimpun informasi tentang kondisi geografis dan penduduk setempat. Selain itu juga untuk melakukan perijinan kegiatan, 3) Survei (survey) adalah adalah metode pengumpulan data primer dengan memberikan pertanyaan-pertanyaan kepada responden individu (Jogianto, 2007), 4) Laporan deskriptif pada kegiatan ini adalah laporan yang menjelaskan tentang bagaimana proses dari kegiatan pengabdian kepada masyarakat yang dijalankan.

\section{Analisis data}

Setelah data responden disusun dalam tabel data, kemudian dilakukan uji kelayan data dengan uji validitas dan Reabilitas dengan tujuan memastikan data secara valid dan reliabel. Data yang valid dan reliabel dilanjutkan uji asumsi klasik pengujian sengan aplikasi SPSS V.24, kemudian Uji-T Uji-F, Uji-Adjusted Square.

\section{HASIL DAN PEMBAHASAN}

\section{Analsis Responden}

Kuesioner yang disediakan untuk 60 responden, tetapi responden yang mengisi kuesioner sebanyak 55 orang, antara lain Laki-laki 6 Orang atau $10.9 \%$ dan Perempuan sebanyak 49 orang atau $89,1 \%$. Berdasarkan usia responden, data usia diklasifikasi berdasarkan rentang usia, yaitu a) usia 15-20 tahun sejumlah 2 Orang atau 3,6\%; b) usia 21-29 tahun sebanyak 1 Orang atau 1,8\%; c) usia 30-39 tahun sebanyak 15 Orang atau 27,3\%; d) usia 4049 tahun sebanyak 16 Orang atau 29,1\%; e) usia 50-59 tahun sebanyak 13 Orang atau $23,6 \%$; f) usia 60-69 tahun sebanyak 8 Orang atau $14,5 \%$. Berikut ini uraian dalam tabel rentang usia responden.

Pendidikan terakhir responden terdiri dari empat jenjang, yakni lulusan SD senayak 39 Orang atau 70,9\%, lulusan SMP sebanyak 8 Orang atau $14,5 \%$; lulusan SMA atau SMK sebanyak 7 Orang atau $12,7 \%$ dan lulusan Sarjan (S1) sebanyak 1 Orang atau 1,8\%. Data dalam tabel dibawah ini menunjukkan bahwa pendidikan tertinggi adalah lulusan Sekolah Dasar. Data pendidikan diuraikan dalam tabel dibawah ini.

Klasifikasi pekerjaan responden paling dominan atau terbanyak adalah pedagang sejumlah 29 orang atau 52,7\%; kemudian diikuti dengan Ibu Rumah Tangga sejumlah 21 Orang atau 38,2\%; buruh 
Tabel 1 Deskriptif statistik

\begin{tabular}{lc|c|c|c|c}
\hline & \multicolumn{5}{c}{ Descriptive Statistics } \\
& $\mathrm{N}$ & Minimum & Maximum & Mean & Std. Deviation \\
\hline Perencanaan & 55 & 8,00 & 27,00 & 14,1273 & 4,54628 \\
\hline Pelaksanaan & 55 & 15,00 & 30,00 & 20,7091 & 5,21633 \\
\hline Pengawasan & 55 & 11,00 & 25,00 & 20,4545 & 3,87211 \\
\hline Evaluasi & 55 & 15,00 & 27,00 & 19,4364 & 3,47352 \\
\hline Kesejahteraan & 55 & 16,00 & 28,00 & 21,2182 & 2,98571 \\
\hline Valid N (listwise) & 55 & & & & \\
\hline
\end{tabular}

sebanyak 4 orang atau 7,3\% dan nelayan 1 orang atau $4,8 \%$. Berikut ini tabel uraian pekerjaan. Data keluaraga yang memiliki jumlah anak terbanyak adalah 6 orang yakni ada 3 keluarga dan jumlah anak 5 orang ada 8 keluarga, kemudia diikuti jumlah anak 4 ada 14 keluarga; jumlah anak 3 orang ada 17 keluarga; jumlah anak 2 orang ada 7 keluarga dan jumlah anak 1 orang ada 6 keluaraga.

\section{Uji Validitas dan Reabilitas}

Pengujian vailiditas dan reabiltas untuk menguji keandalan dan kualitas data olahan dari kuesioner dan pengolahan data lanjutan wajib menggunakan data yang valid dan reabilitas. Hasil pengujian semua data valid dan reliabel, dibuktikan dengan uji reabiltas nilai Cronbach's Alpha > 0,60; antara lain Perencanaan 0,753 > 0,600; Pelaksanaan 0,767 > 0,60; Pengawasan $7,27>0,60$; Evaluasi 0,707 > 0,60; Kesejahteraan 0,717 >>0,60. Uji valitas semua variabel memiliki nilai korelasi > 0,05 dengan tingkat signifikansi $0,05>$ 0,000 .

\section{Statistik Deskriptif}

Sesuai dengan tujuan dan kegiatan pengabdian kepada masyarakat ini, kami telah melakukan beberapa tahapan kegiatan, yaitu konsultasi dengan perangkat desa kelurahan dan masyarakat pelaku usaha untuk mendapatkan informasi yang mendukung kegiatan PKM ini dan menyebarkan kuesioner untuk mengukur pelaksanaan usaha ekonomi produktif. Output statistik deskriptif di uraiakan dalam tabel dibawah ini.

Hasil output SPSS V.24 dalam tabel diatas, menunjukkan bahwa jawaban responden paing baik adalah pelaksanaan kegiatan usaha ekonomi produktif sebesar 30 point dan rata-rata 20,7091 dengan standar deviasi 5,21633, sedang nilai responden terendaha dalah perencanaan karena msayarakat kurang dilibatkan dalam perancanaan usaha ekonomi produktif.

\section{Usaha Ekonomi Produktif Melalui Usaha Kecil Dan Menengah Maupun Kelompok Usaha Bersama Pada Masyarakat Kelurahan Kampung Bugis,}

Kelurahan kampong Bugis pernah melakukan usaha ekonomi produktif akan tetapi belum memenuhi tujuan yang akan dicapai, karena kurang sistem, manajemen dan sumber daya manusia untuk mengelolah dan mengevaluasi kegiatan usaha ekonomi produktif tersebut. Solusi mengatasi permasalahan tersebut dapat dilakukan dengan dua metode pendekatan kegiatan kemasyarakatan untuk pemecahan masalah/solusi, sebagai berikut; 1) Memberikan motivasi Mengenai Usaha Ekonomi Produktif (UEP). Melalui kegiatan pengabdian kepada masyarakat dengan kegiatan sosialisasi, pelatihan dan simulasi kewirausahaan untuk meningkatkan perekonomian masyarakat, 
sehingga akan membangkaitkan motivasi dan semangat untuk berwirausaha. Adapun sasaran kegiatan ini antara lain a) Memberi pemahaman mengenai kewirausahaan sebagai modal awal dalam mengembangkan usaha, b) Bentuk kegiatannya adalah pelatihan motivasi berusaha dan kewirausahaan, c) Mengembangkan usaha ekonomi produktif dalam bentuk Kelompok Usaha Bersama yang didasarkan pada potensi kelompok.

Sebelum melakukan usaha ekonomi produktif tersebut terlebih dahulu memberikan pelatihan/simulasi mengenai usaha ekonomi produktif (UEP). Pelatihan dengan simulasi berwirausaha dengan tujuan : a) Untuk membina pembentukan pemberdayaan Usaha Kecil Dan Menengah Dalam Kelompok Usaha Bersama (KUBE) Mengenai Ekonomi Masyarakat Kelurahan Kampung Bugis, b) Menumbuhkan semangat berwirausaha bagi masyarakat pesisir di daerah Kelurahan Kampung Bugis melalui pembentukan kelompok usaha bersama, c) Memberdayakan potensi masyarakat miskin dalam meningkatkan pendapatan keluarga melalui peningkatan usaha ekonomi produktif, d) Merintis terbentuknya inkubator pengusaha kecil dan menengah di Kelurahan Kampung Bugis.

\section{Pemberdayaan Usaha Ekonomi Produktif Dalam Meningkatkan Kesejahteraan Masyarakat Pesisir}

Pengujian usaha ekonomi produktif dilakuan berdasarkan tiga indikator efektif pelaksanaan usaha ekonomi prodif yaitu; Perencanaan, Pelaksanaan, Pengawasan dan Evaluasi. Hasil pengujian dengan SPSS V.24 diuraikan dalam tebel dibawah ini.
Tabel 2 Uji Parsial (Uji-T)

\begin{tabular}{|c|c|c|c|c|c|}
\hline \multicolumn{6}{|c|}{ Coefficients $^{\mathbf{a}}$} \\
\hline & \multicolumn{2}{|c|}{$\begin{array}{l}\text { Unstandardize } \\
\text { d Coefficients }\end{array}$} & \multirow{2}{*}{$\begin{array}{c}\text { Standardized } \\
\text { Coefficients } \\
\text { Beta }\end{array}$} & \multirow[b]{2}{*}{$\mathrm{t}$} & \multirow[b]{2}{*}{ Sig. } \\
\hline Model & $\mathrm{B}$ & $\begin{array}{l}\text { Std. } \\
\text { Error }\end{array}$ & & & \\
\hline 1 (Constant) & 8,320 & 2,010 & & 4,138 &, 000 \\
\hline Perencanaan &,- 066 & ,068 &,- 100 &,- 971 & ,336 \\
\hline Pelaksanaan & ,360 & ,059 & ,630 & 6,081 &, 000 \\
\hline Pengawasan & ,148 & ,080 & ,193 & 1,865 &, 068 \\
\hline Evaluasi &, 171 & ,087 & , 199 & 1,962 &, 055 \\
\hline
\end{tabular}

a. Dependent Variable: Kesejahteraan

Hasil pengujian secara parsial (Uji-T) membuktikan bahwa usaha ekonomi produktif berdasarkan pelaksanaan usaha ekonomi produktif berpengaruh signifikan sebesar $36 \%$ terhadap peningkatan kesejahteraan masyarakat pesisir di Kampung Bugis, karena mayarakat dapat melakukan usaha ekonomi rakyat sesuai dengan kemampuan dan keahlian, sehingga mampu menciptakan usaha masyarakat yang bisa diterima lingkungan serta sesuai dengan permintaan kebutuhan masyarakat dan lingkungan saat ini.

Sedangkan usaha ekonomi produktif berdasarkan perencanaan, pengawasan dan evaluasi tidak berpengaruh signifikan terhadap peningkatan kesejahteraan masyarakat pesisir di Kampung Bugis, karena dalam menentukan perencanaan harus mengikuti petunjuk dan aturan pemerintah, masyarakat hanya menerima program pendanaan yang sudah dibuat dan ditentukan pemerintah khusunya nilai anggaran yang berikan kepada masyarakat untuk usaha ekonomi produktif, sering ditemui bahwa pemberian modal usaha kepada masyarakat tidak tepat sasaran sehingga penggunaan bantuan modal tersebut tidak maksimal dan resiko pengembalian atas pengunaan modal sangat ringan. Hal lainnya adalah kurangnya perencanaan, pengawasan dan evaluasi dikarenakan usaha ekonomi produktif belum didampingi secara tuntas hingga benar teruji, sehingga masyarakat 
memiliki pemahan yang tidak maksimal, termasuk pengasan dan evaluasi yang tidak maksimal. Model persamaan regresi berganda diformulasikan sebagai berikut :

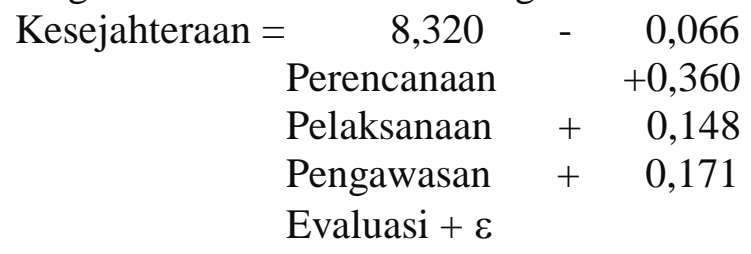

Pengujian lanjutan Pemberdayaan Usaha Ekonomi Produktif Dalam Meningkatkan Kesejahteraan Masyarakat Persisir Kelurahan Kampung Bugis, Tanjungpinang dilakukan Uji Simultan (Uji-F) dan uji Determinasi dalam tabel dibawah ini.

Tabel 3 Uji Simultan (Uji-F)

\begin{tabular}{|c|c|c|c|c|c|c|}
\hline \multicolumn{7}{|c|}{$\operatorname{ANOVA}^{a}$} \\
\hline \multicolumn{2}{|c|}{ Model } & $\begin{array}{l}\text { Sum of } \\
\text { Squares }\end{array}$ & df & $\begin{array}{l}\text { Mean } \\
\text { Square }\end{array}$ & $\mathrm{F}$ & Sig. \\
\hline \multirow{3}{*}{1} & Regression & 298,314 & 4 & 74,578 & 20,369 &, $000^{\mathrm{b}}$ \\
\hline & Residual & 183,068 & 50 & 3,661 & & \\
\hline & Total & 481,382 & 54 & & & \\
\hline
\end{tabular}

a. Dependent Variable: Kesejahteraan

b. Predictors: (Constant), Evaluasi, Pengawasan, Perencanaan, Pelaksanaan

Tabel 4 Uji Determinasi

\begin{tabular}{|c|c|c|c|c|}
\hline \multicolumn{5}{|c|}{ Model Summary } \\
\hline Model & $\mathrm{R}$ & $\begin{array}{c}\mathrm{R} \\
\text { Square }\end{array}$ & $\begin{array}{l}\text { Adjusted R } \\
\text { Square }\end{array}$ & $\begin{array}{c}\text { Std. Error of the } \\
\text { Estimate }\end{array}$ \\
\hline 1 &, $787^{\mathrm{a}}$ &, 620 & ,589 & 1,91347 \\
\hline
\end{tabular}

Pengujian secara bersamaan/simultan (Uji F) uji Anova, bahwa nilai Fhitung sebsesar 20,369 dan nilai signifikan F-nya adalah sebesar 0,000 (signifikan $\mathrm{F}<$ a.0,05) maka secara bersamaan usaha ekonomi produktif melalui perencanaan, pengawasan, pelaksanaan dan evaluasi berpengaruh signifikan terhadap peningkatan kesejahteraan. Secara keseluruhan bahwa peningkatan kesejahteraan masyarakat kelurahan kampung Bugis dipengaruhi oleh usaha ekonomi produktif (perencanaan, pengawasan, pelaksanaan dan evaluasi) sebesar 58,9\%, selainnya diluar dari variabel ini.

\section{Menumbuhkan semangat berwirausaha dalam Usaha Ekonomi Produktif bagi masyarakat pesisir Kelurahan Kampung Bugis.}

Staraegi Menumbuhkan semangat berwirausaha dalam usaha ekonomi produktif bagi masyarakat pesisir di Kelurahan Kampung Bugis melalui tiga capaian kegiatan antara lain adalah :

a. Membuat Target Kegiatan; target kegitan untuk menghasilkan pengusaha kecil dan menengah bagi masyarakat yang tinggal di daerah persisir Kelurahan Kampung Bugis, Tanjungpinang merupakan bagian dari target kegiatan pengabdian kepada masyarakat yang akan kami lakukan. Dalam upaya memberdayakan masyarakat tersebut dapat dilihat dari tiga sisi, yaitu: Pertama, menciptakan suasana atau iklim yang memungkinkan masyarakat berkembang (enabling). Kedua, memperkuat potensi atau daya yang dimiliki masyarakat (empowering). Ketiga, memberdayakan mengandung pula arti melindungi. Pemberdayaan dan Pembangunan di Indonesia yang dilaksanakan secara berkesinambungan bertujuan untuk meningkatkan kesejahteraan rakyat secara adil dan merata.

b. Pemberdayaan Masyarakat; setelah target tercapai akan munculnya pemahaman pengusaha kecil dan menengah kemudian dilanjutkan untuk berwirausaha dalam meningkatkan ekonomi masyarakat yang tinggal didaerah pesisir, adapun pemberdayaaan melalui; a) Pembinaan pemberdayaan 
pembentukan usaha kecil dan menengah dalam kelompok usaha bersama (KUBE) mengenai ekonomi masyarakat Kelurahan Kampung Bugis, b) Menumbuhkan semangat berwirausaha bagi masyarakat pesisir di daerah Kelurahan Kampung Bugis melalui pembentukan kelompok usaha bersama, c) Memberdayakan potensi masyarakat miskin dalam meningkatkan pendapatan keluarga melalui peningkatan usaha ekonomi produktif. d) pemberdayaan untuk merintis terbentuknya inkubator pengusaha kecil dan menengah di Kelurahan Kampung Bugis.

c. Pembinaan dan Pengembangan; pembinaan untuk mendorong terciptanya diversifikasi usaha yang kompetitif, peningkatan kemampuan manajemen dan Peningkatan dan perluasan jaringan pemasaran dan hubungan sinergitas antara Industri Kecil dengan Industri besar. Sedangkan Pengembangan ; adalah untuk meningkatan SDM dan Kelembagaan melalui Pendidikan Latihan Ketrampilan Usaha dan Manajemen Usaha, penciptaan jaringan kerjasama dan kemitraan usaha yang didukung oleh Organisasi Masyarakat setempat, Swasta dan Perguruan Tinggi dan Memperluas akses kepada sumber permodalan khususnya Perbankan dan Lembaga Permodalan Masyarakat lainnya.

\section{KESIMPULAN}

Berdasarkan hasil pengujian data yang diproses SPSS V.24 dan analisis informasi hasil pengabdian sesuai dengan tujuan, maka hasil penelitian adalah : Usaha ekonomi produktif melalui usaha kecil dan menengah maupun kelompok usaha bersama pada masyarakat Kelurahan Kampung Bugis sudah pernah dilakukan tetapi belum memenuhi tujuan yang akan dicapai, Stertegi yang dilakukan adalah a) pembinaan dan pemberdayaan usaha ekonomi produktif dengan kuntinuitas mengembangkan usaha, b) pelatihan dan motivasi kewirausahaan, mengembangkan usaha ekonomi produktif dalam bentuk Kelompok Usaha Bersama yang didasarkan pada potensi kelompok. Pemberdayaan Usaha Ekonomi Produktif Dalam Meningkatkan Kesejahteraan Masyarakat Pesisir, Hasil pengujian secara parsial (Uji-T) membuktikan bahwa usaha ekonomi produktif berdasarkan pelaksanaan usaha ekonomi produktif berpengaruh signifikan sebesar 36\% terhadap peningkatan kesejahteraan masyarakat pesisir di Kampung Bugis, karena mayarakat dapat melakukan usaha ekonomi rakyat sesuai dengan kemampuan dan keahlian, sehingga mampu menciptakan usaha masyarakat yang bisa diterima lingkungan serta sesuai dengan permintaan kebutuhan masyarakat dan lingkungan saat ini. Sedangkan usaha ekonomi produktif berdasarkan perencanaan, pengawasan dan evaluasi tidak berpengaruh signifikan terhadap peningkatan kesejahteraan masyarakat pesisir di Kampung Bugis, karena kurangnya pembinaan dan pemberdayaan masyarakat untuk pelaksanaan usaha ekonomi produktif. Menumbuhkan semangat berwirausaha dalam Usaha Ekonomi Produktif bagi masyarakat pesisir Kelurahan Kampung Bugis melalui tiga capaian kegiatan antara lain adalah a) Membuat Target Kegiatan, b) Pemberdayaan Masyarakat, c) Pembinaan dan Pengembangan usaha yang kompetitif dan Memperluas akses kepada sumber permodalan khususnya Perbankan dan Lembaga Permodalan Masyarakat lainnya

\section{DAFTAR PUSTAKA}

Istiana Hermawati, dkk. 2011. Evaluasi Program Kelompok Usaha Bersama $(K U B E)$. Yogyakarta: BP2P3KS. 
Kartasasmita, Ginandjar. 2000.

Pembangunan Untuk Rakyat

Memadukan Pertumbuhan dan

Pemerataan.Jakarta: PT Pustaka Cidesindo.

Mardikanto, Totok \& Poerwoko Soebiato, 2012. Pemberdayaan Masyarakat dalam Perspektif Kebijakan Publik (edisi revisi), Bandung: Alfabeta

Mifthachul Huda. 2009. Pekerjaan Sosial dan Kesejahteraan Sosial. Yogyakarta: Pustaka Pelajar.

Margono Slamet. 2003. Membentuk Pola Perilaku Manusia Pembangunan. IPB Press. Bogor.

Diterima : 5 September 2018

Disetujui : 8 November 2018 